[Berliner entomologische Zeitschrift XVIII. 1874.]

\title{
Veränderung der Fauna und Flora der Mannsfelder Seen.
}

Für die entomologischen Besucher des Salzsees bei Eisleben dürfte die Mittheilung gewifs von Interesse sein, dafs auch der daselbst gelegene sogenannte "süfse See" seit einigen Jahren einen bedeutenden Salzgehalt zeigt, welcher den des sogenannten "Salzsees" bei Erdeborn vielleicht schon übertrifft, der überhaupt auch von Jahr zu Jahr an Salzgehalt zu verlieren scheint. Die Ursache dieser Erscheinung ist wohl darin zu suchen, dafs der den grofsen See speisende Erdeborner Stollen durch unterirdische Verschüttung nicht mehr soviel Salz mitführt und auch weniger Wasser wie früher enthält, während der in den süfsen See mündende Stollen durch diese Verschüttung mehr und salzhaltigeres Wasser - er beginnt unweit des Anfanges vom anderen Stollen - enthält. Die Folgen dieser Veränderungen zeigen sich seit einigen Jahren in auffallender Weise, indem die Salzflora an dem grofsen See immer mehr zurückgeht und die berühmte Salzfläche bei Erdeborn mehr und mehr zu Ackerland umgewandelt wird. So sehr nun das sichtbar zunehmende Verschwinden der Salzflora und in Folge dessen auch der Salzthiere im entomologischen Interesse $\mathrm{zu}$ beklagen ist, so erfreulich ist die Erscheinung, dafs umgekehrt am "süfsen See" sich bereits schon eine bedeutende Salzflora gebildet hat. Zwischen den Ortschaften Lüttgendorf und Wormsleben, etwa $\frac{3}{4}$ Stunde von Erdeborn, findet sich ein ziemlich ausgedehnter Salzanger, auf welchem ich bei meinem ganz flüchtigen Besuche im vorigen Jahre die alten Bekannten vom neueren See, wie Bledius unicornis, bicornis, tricornis, Anthicus humilis, Pogonus chalceus etc. in grofser Menge und unter Erdschollen auch einzeln Amara convexiuscula, Chlaenius holosericeus etc. antraf.

Die vorstehenden Mittheilungen verdanke ich zum Theil der Güte des Herrn Pastor Heine jun. in Erdeborn, welcher schon manchem Entomologen, welcher den See besuchte, mit seinen Erfabrungen in freundlichster Weise zur Hand gegangen ist.

Mülverstedt, den 26. Januar 1874.

Max v. Hopffgarten. 


\section{$2 \mathrm{BHL}$ Biodiversity Heritage Library}

Hopffgarten, Max von. 1874. "Veränderung der Fauna und Flora der Mannsfelder Seen." Berliner entomologische Zeitschrift / herausgegeben von dem Entomologischen Vereine in Berlin 18(102),137-137. https://doi.org/10.1002/mmnd.18740180125.

View This Item Online: $\underline{\text { https://www.biodiversitylibrary.org/item/36410 }}$

DOI: https://doi.org/10.1002/mmnd.18740180125

Permalink: https://www.biodiversitylibrary.org/partpdf/209990

\section{Holding Institution}

Smithsonian Libraries

\section{Sponsored by}

Smithsonian

\section{Copyright \& Reuse}

Copyright Status: Public domain. The BHL considers that this work is no longer under copyright protection.

This document was created from content at the Biodiversity Heritage Library, the world's largest open access digital library for biodiversity literature and archives. Visit BHL at https://www.biodiversitylibrary.org. 